\title{
RÓI LOẠN CHỨC NĂNG HÔ HẤP CỦA BẸNH NHÂN BỤI PHỔ SILIC TẠI BỆNH VIỆN PHỔ TRUNG ƯƠNG NĂM 2020
}

\author{
Khương Văn Duy, Lê Thị Thanh Xuân, Nguyễn Ngọc Anh, \\ Nguyễn Thanh Thảo, Nguyễn Thị Quỳnh ${ }^{\bowtie}$, Phan Mai Hương
}

Viện Đào tạo YHDP và YTCC, Trường Đại học Y Hà Nội

Nghiên cứu được tiến hành tại Khoa bệnh phổi nghề nghiệp, Bệnh viện Phổi Trung ương nhằm mô tả các rối loạn thông khí phổi ở bệnh nhân mắc bệnh bụi phổi silic. Thiết kế nghiên cứu mô tả cắt ngang được áp dụng trên 86 người bệnh bằng phỏng vấn trực tiếp và phân tích hô hấp ký từ bệnh án của đối tượng nghiên cứu. Kết quả cho thấy 23,3\% đối tượng nghiên cứu có rối loạn thông khí hạn chế, 23,3\% có rối loạn thông khí tắc nghẽn và 12,7\% có rối loạn thông khí hôn hợp. Trong số đối tượng có hội chứng hạn chế, hơn một nửa là ở mức độ nhẹ (60,0\%), rối loạn thông khí hạn chế mức độ nặng chiếm 30,0\% và rối loạn thông khí mức độ vừa chiếm 10,0\%. Trong số đối tượng có hội chứng tắc nghẽn 45\% là mức độ nặng trở lên, rối loạn thông khí tắc nghẽn mức độ vừa cũng chiếm $45 \%$ và mức độ nhẹ chỉ chiếm 10,0\%. Cần có những hỗ trợ và hướng dẫn về các biện pháp dự phòng bệnh bụi phổi silic cho người lao động.

Từ khóa: bệnh bụi phổi silic, Bệnh viện Phổi Trung ương, rối loạn chức năng hô hấp.

\section{I. ĐẠT VẤN ĐỀ}

Bụi phổi silic là bệnh nghề nghiệp xảy ra do hít phải bụi có chứa silic trong môi trường lao động. Đặc điểm của bệnh là xơ hóa và phát triển các tổn thương dạng nốt ở phổi. ${ }^{1,2}$ Cho đến nay bệnh bụi phổi chưa có thuốc điều trị đặc hiệu, bệnh tiến triển theo thời gian gây hiện tượng xơ hóa phổi không hồi phục. Công nhân mắc bệnh bụi phổi thường dễ mắc các bệnh như lao phổi, viêm phổi và ung thư phổi. Bệnh tiến triển gây ra các biến chứng như lao, tâm phế mạn, suy hô hấp. Suy hô hấp cũng là một biến chứng thường gặp do biến đổi xơ hóa và khí thũng rộng, thường kèm theo tâm phế mạn do huyết áp cao ở tiểu tuần hoàn, hậu quả của sự phá hủy lưới mao mạch và sự co thắt các mao quản phổi do giảm oxy huyết. ${ }^{3}$

Bệnh nhân bụi phổi silic hay gặp rối loạn

Tác giả liên hệ: Nguyễn Thị Quỳnh

Viện Đào tạo YHDP và YTCC, Trường Đại học Y Hà Nội

Email: nguyenthiquynhhmu@gmail.com

Ngày nhận: 01/04/2021

Ngày được chấp nhận: 19/07/2021 thông khí (RLTK) hạn chế, ở giai đoạn cuối gây rối loạn thông khí tắc nghẽn và rối loạn thông khí hỗn hợp do bệnh kéo dài kết hợp với những tổn thương khác như tràn dịch màng phổi, tràn khí màng phổi, liên kết đám mờ, co kéo các cơ quan trong lồng ngực, hạch trung thất to. Chúng khiến phổi không nở ra hoàn toàn khi hít vào tối đa, dung tích phổi giảm dẫn đến hội chứng rối loạn thông khí hạn chế. Tuy nhiên rối loạn thông khí thường không đi đôi với hình ảnh tổn thương trên phim Xquang, khi có biểu hiện trên lâm sàng bởi tình trạng khó thở thì chức năng hô hấp của bệnh nhân thường có rối loạn ở mức độ vừa và nặng. ${ }^{4}$ Các nghiên cứu đã chỉ rằng mức độ nặng của bệnh bụi phổi silic tỷ lệ thuận với tình trạng rối loạn chức năng hô hấp. ${ }^{5}$ So với với bệnh bụi phổi amiăng và bệnh bụi phổi than, bệnh bụi phổi silic có mức độ giảm khả năng khuếch tán khí $\mathrm{CO}$ qua màng mao mạch phế nang tương đương, nhưng FEV1/ FVC lại giảm nhiều hơn bệnh bụi phổi amiang. Trên những bệnh nhân bụi phổi hút thuốc cũng có mức độ suy giảm chức năng hô hấp trầm 
trọng hơn. ${ }^{6}$ Hội chứng rối loạn thông khí tắc nghẽn xảy ra khi có các yếu tố làm tăng sức cản đường thở như hạch trung thất to chèn ép vào các nhánh phế quản, cản trở sự thở ra có liên quan đến sự tiếp xúc tích lũy với bụi silic. ${ }^{7,8}$ Đánh giá rối loạn chức năng hô hấp có ý nghĩa rất quan trong trong chẩn đoán mức độ bệnh, giúp chẩn đoán, điều trị hợp lý, theo dõi tiến triển và tiên lượng bệnh bụi phổi silic. Do vậy nghiên cứu được thực hiện với mục tiêu mô tả các rối loạn chức năng hô hấp của bệnh nhân bụi phổi silic tại Bệnh viện Phổi Trung ương năm 2020, từ đó đưa ra các giải pháp điều trị cho bệnh nhân mắc bệnh bụi phổi silic nhằm làm chậm quá trình xơ hóa phổi và cải thiện chất lượng cuộc sống cho bệnh nhân.

\section{II. ĐÓl TƯợNG VÀ PHƯƠNG PHÁP}

\section{1. Đối tượng}

Bệnh nhân mắc bệnh bụi phổi silic được điều trị tại Bệnh viện Phổi Trung ương trong thời gian từ tháng 6 năm 2020 đến tháng 12 năm 2020 với tiêu chuẩn lựa chọn là tất cả bệnh nhân được chẩn đoán mắc bệnh bụi phổi silic đang điều trị tại Khoa Bệnh phổi nghề nghiệp - Bệnh viện phối Trung ương có phim chụp Xquang lồng ngực 35 x $43 \mathrm{~cm}$ đảm bảo chất lượng loại 1, loại 2 và loại 3 theo tiêu chuẩn ILO 2000 và 2011; đối tượng đồng ý tham gia nghiên cứu. Tiêu chuẩn loại trừ là những bệnh nhân mắc bệnh bụi phổi silic không đồng ý tham gia nghiên cứu.

\section{Phương pháp}

\section{Thiết kế nghiên cứu}

Thiết kế nghiên cứu cắt ngang.

\section{Địa điểm nghiên cứu}

Nghiên cứu được tiến hành tại Khoa bệnh phổi nghề nghiệp - Bệnh viện Phổi Trung ương.

\section{Thời gian nghiên cứu}

Nghiên cứu được tiến hành từ tháng 5 năm 2020 đến tháng 12 năm 2020, trong đó thời gian thu thâp số liệu vào tháng 6 năm 2020 đến tháng 12 năm 2020.

\section{Cỡ mẫu và chọn mẫu}

Chọn mẫu toàn bộ bệnh nhân mắc bệnh bụi phổi silic đang điều trị tại Khoa bệnh phổi nghề nghiệp - Bệnh viện Phổi Trung ương từ tháng 6 năm 2020 đến tháng 12 năm 2020 và đạt tiêu chuẩn lựa chọn. Thực tế có 86 bệnh nhân bụi phổi silic vào điều trị tại Khoa bệnh phổi nghề nghiệp Bệnh viện Phổi Trung ương trong thời gian thu thập số liệu và có phim Xquang lồng ngực $35 \times 43 \mathrm{~cm}$ đảm bảo chất lượng loại 1 và loại 2 theo tiêu chuẩn ILO 2000 và 2011.9,10

Thu thập số liệu: thông tin của đối tượng nghiên cứu bao gồm: họ tên, năm sinh, công việc, tuổi nghề, các chỉ số chức năng hô hấp (VC, FVC, FEV1/FVC...) các chỉ số tổn thương trên phim Xquang bụi phổi tại thời điểm được đo và chụp sớm nhất. Kết quả đọc phim đã được chuyên gia đọc phim bệnh bụi phổi đọc và phân loại tổn tổn thương theo "Hướng dẫn sử dụng bảng phân loại quốc tế ILO - 2000 và 2011 phim Xquang các bệnh bụi phổi”. 9, 10

\section{Xử lý số liệu}

Số liệu sau khi được thu thập sẽ được nhập bằng phần mềm Epi Data 3.1 để hạn chế sai sót nhập liệu, sau đó sẽ được chuyển vào phần mềm SPSS 20.0 để phân tích. Thống kê mô tả được áp dụng để trình bày các thông tin chung, các rối loại chức năng hô hấp của đối tượng nghiên cứu dựa trên kết quả đo hô hấp ký.

Phân loại rối loạn thông khí hạn chế dựa vào chỉ số dung tích sống (VC) hoặc FVC của Hội lồng ngực Mỹ.

VC (dung tích sống) từ 60 đến < 80\%: hội chứng hạn chế mức độ nhẹ.

VC từ 40 đến < 59\%: hội chứng hạn chế mức độ vừa.

VC < 40\%: hội chứng hạn chế mức độ nặng.

Phân loại rối loạn thông khí tắc nghẽn dựa 
vào chỉ số $\mathrm{FEV}_{1}$ (thể tích thở ra gắng sức trong giây đầu):

- $\mathrm{FEV}_{1} \geq 80 \%$ : rối loạn thông khí tắc nghẽn nhẹ.

- FEV 1 từ 50 đến < 80\%: rối loạn thông khí tắc nghẽn trung bình.

- $F E V_{1}$ từ 30 đến < 50 \%: rối loạn thông khí tắc nghẽn nặng.

- $\mathrm{FEV}_{1}<30 \%$ : rối loạn thông khí tắc nghẽn rất nặng.

Rối loạn thông khí hỗn hợp khí có cả rối loạn thông khí hạn chế và tắc nghẽn.

\section{4. Đạo đức nghiên cứu}

Nghiên cứu thuộc nhánh đề tài nhà nước "Nghiên cứu đặc điểm dịch tễ học phân tử, yếu tố nguy cơ và ứng dụng kỹ thuật tiên tiến trong chẩn đoán sớm bệnh bụi phổi silic tại Việt Nam" thuộc chương trình "Nghiên cứu ứng dụng và phát triển công nghê tiên tiến phục vụ bảo vệ chăm sóc sức khỏe cộng đồng" Mã số: KC.10.33/16-20 do Viện Đào tạo $Y$ học Dự phòng và $Y$ tế Công cộng thực hiện. Đề tài được Hội đồng đạo đức Trường Đại học $Y$ Hà Nội thông qua, mã số 4218/HMUIRB ngày 16/11/2018. Đối tượng nghiên cứu có thể từ chối tham gia nghiên cứu ở bất kỳ thời điểm nào của nghiên cứu. Mọi thông tin cá nhân đều được giữ bí mật và chỉ sử dụng vào mục đích nghiên cứu. Các dữ liệu được bảo mật, chỉ có nhà nghiên cứu mới truy cập được.

\section{KÉT QUẢ}

\section{1. Đặc điểm chung của đối tượng nghiên cứu}

Bảng 1. Đặc điểm của đối tượng nghiên cứu

\begin{tabular}{ccc}
\hline Biến số & Số lượng & Tỷ lệ (\%) \\
\hline \multirow{2}{*}{ Tuổi đò̀i } & Trung bình \pm SD & Min - Max \\
\cline { 2 - 3 } & $43,76 \pm 10,28$ & $25-72$ \\
\hline Nhóm tuổi đời & & 7,0 \\
\hline$<30$ tuổi & 6 & 38,4 \\
\hline 30 - 39 tuổi & 33 & 30,2 \\
\hline 40 - 49 tuổi & 26 & 24,4 \\
\hline$\geq 50$ tuổi & 21 & Min - Max \\
\hline Tuổi nghề & Trung bình \pm SD & $2-40$ \\
\hline$<5$ năm & $8,31 \pm 7,56$ & 50,0 \\
\hline 5 - 9 & 43 & 31,3 \\
\hline 10 - 14 năm & 27 & 7,0 \\
\hline 15 - 19 năm & 6 & 7,0 \\
\hline$\geq 20$ năm & 6 & 4,7 \\
\hline Tổng số & 4 & 100 \\
\hline
\end{tabular}


Kết quả bảng 1 cho thấy tuổi trung bình của đối tượng nghiên cứu là 43,76 $\pm 10,28$ tuổi, trong đó nhóm tuổi từ 30 đến 49 tuổi chiếm tỷ lệ cao nhất với 68,6\%. Trung bình tuổi nghề của đối tượng nghiên cứu là $8,31 \pm 7,56$ năm, trong đó một nửa là có tuổi nghề dưới 5 năm. Tỷ lệ đối tượng có tuổi nghề từ 20 năm trở lên chiếm 4,7\%.

2. Phân bố nghề nghiệp của đối tượng nghiên cứu

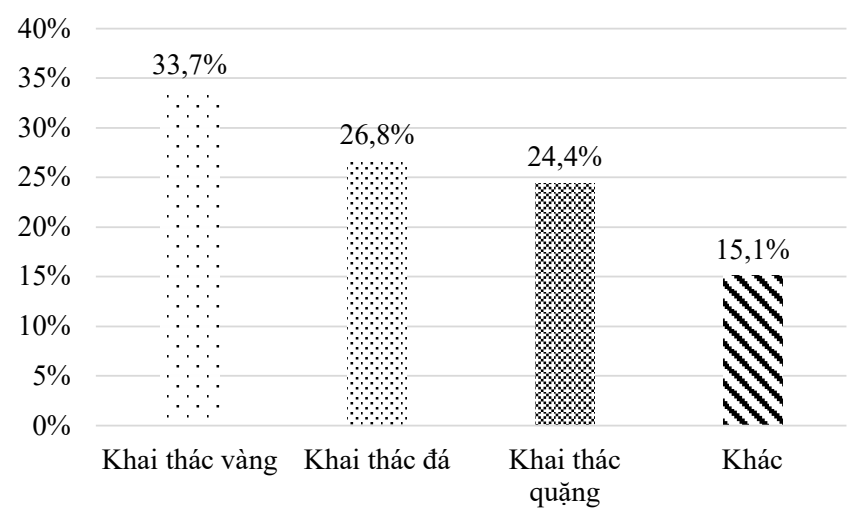

\section{Biểu đồ 1. Cơ cấu công việc của đối tượng nghiên cứu}

Trong tổng số đối tượng tham gia nghiên cứu, đối tượng làm khai thác vàng chiếm tỷ lệ cao nhất $(33,7 \%)$ tiếp theo là khai thác đá $(26,8 \%)$, khai thác quặng $(24,4 \%)$, công việc khác như làm cát, khắc bia mộ chiếm 15,1\%.

3. Mật độ tổn thương đám mò̀ nhỏ trên phim Xquang của đối tượng nghiên cứu

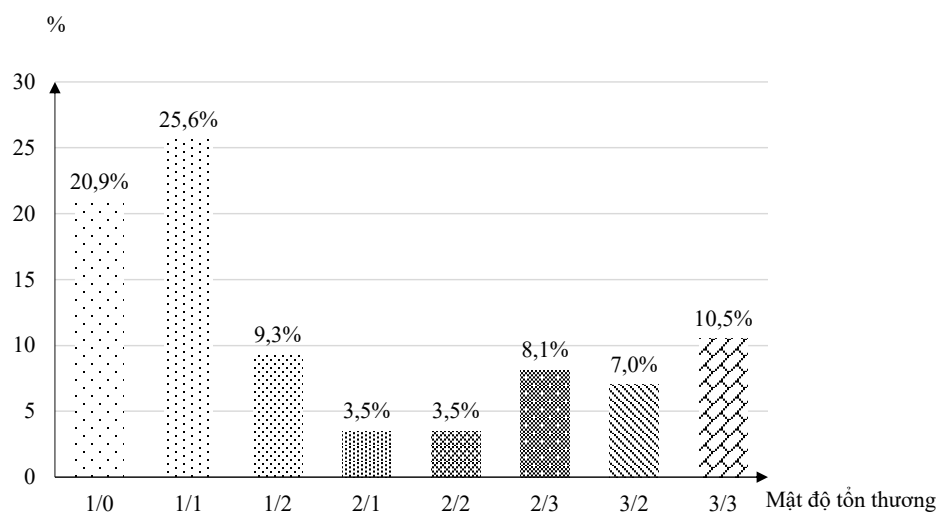

Biểu đồ 2. Mật độ tổn thương đám mò̀ nhỏ trên phim Xquang của đối tượng nghiên cứu

Kết quả biểu đồ 2 cho thấy, mật độ tổn thương đám mờ nhỏ trên phim Xquang $1 / 1$ chiếm tỷ lệ cao nhất $(25,6 \%)$ tiếp theo là $1 / 0$ (20,9\%). Tổn thương mật độ $3 / 3$ chiếm 10,5\%; $3 / 2$ chiếm $7 \%$. 


\section{Thực trạng rối loạn thông khí của đối tượng nghiên cứu}

Bảng 2. Thực trạng rối loạn thông khí của đối tượng nghiên cứu

\begin{tabular}{ccc}
\hline Biến số & Số lượng $(\mathbf{n})$ & Tỷ lệ (\%) \\
\hline RLTK hạn chế & 20 & 23,3 \\
\hline Nhẹ & 12 & 60,0 \\
\hline Vừa & 2 & 10,0 \\
\hline Nặng & 6 & 30,0 \\
\hline RLTK tắc nghẽn & 20 & 23,3 \\
\hline Nhẹ & 2 & 10,0 \\
\hline Vừa & 9 & 45,0 \\
\hline Nặng & 4 & 20,0 \\
\hline Rất nặng & 5 & 25,0 \\
\hline RLTK hỗn hợp & 11 & 12,8 \\
\hline Bình thường & 35 & 40,7
\end{tabular}

Kết quả bảng 2 cho thấy $23,3 \%$ đối tượng nghiên cứu có rối loạn thông khí hạn chế, $23,3 \%$ có rối loạn thông khí tắc nghẽn và $12,7 \%$ có rối loạn thông khí hỗn hợp. Trong số đối tượng có hội chứng hạn chế, hơn một nửa là ở mức độ nhẹ $(60,0 \%)$, rối loạn thông khí hạn chế mức độ nặng chiếm $30,0 \%$ và rối loạn thông khí mức độ vừa chiếm 10,0\%. Trong số đối tượng có hội chứng tắc nghẽn, tắc nghẽn mức độ vừa chiếm tỷ lệ cao nhất $(45,0 \%)$, tiếp đến là mức độ rất nặng $(25,0 \%)$, sau đó là mức độ nặng $(20,0 \%)$ và tắc nghẽn mức độ nhẹ $(10,0 \%)$.

\section{BÀN LUẬN}

Ở những bệnh nhân mắc bệnh bụi phổi silic rối loạn thông khí thường biểu hiện muộn hơn so với tổn thương trên phim X-quang, nếu bệnh nhân đến cơ sở y tế mà đã có rối loạn thông khí thì khi đó bệnh đã ở những giai đoạn vừa và nặng. Bụi silic đã xâm nhập vào phổi, lâu ngày không đào thải được gây viêm mạn tính các tiểu phế quản cuối cùng biểu hiện bằng hội chứng tắc nghẽn trên lâm sàng. Theo thời gian, lượng bụi lớn ứ đọng trong các phế nang khiến dung tích phổi giảm và biểu hiện bởi hội chứng hạn chế hoặc hỗn hợp. Kết quả nghiên cứu cho thấy $23,3 \%$ đối tượng nghiên cứu có rối loạn thông khí hạn chế, 23,3\% có rối loạn thông khí tắc nghẽn và $12,7 \%$ có rối loạn thông khí hỗn hợp. Kết quả này cao hơn nghiên cứu của Nguyễn Ngọc Sơn ${ }^{11}$ và một số nghiên cứu khác trên công nhân mỏ than, 89,11\% được báo cáo là bình thường; $2,9 \%$ có rối loạn thông khí tắc nghẽn và $1,11 \%$ có rối loạn thông khí hạn chế12 do đối tượng nghiên cứu của chúng tôi đều đã mắc bệnh bụi phổi nên chức năng hô hấp sẽ rối loạn nhiều hơn khi nghiên cứu trên quần thể ngoài cộng đồng. Kết quả này phù hợp với đặc điểm bệnh lý của bệnh bụi phổi silic là xơ hóa phổi không hồi phục, dẫn đến giảm dung tích phổi và gây ra hội chứng hạn chế. Tuy nhiên kết quả của chúng tôi lại có tỷ lệ đối tượng có 
rối loạn thông khí tắc nghẽn bằng rối loạn thông khí hạn chế và cao hơn rối loạn thông khí hỗn hợp. Điều này không đồng nhất với y văn có thể do sai số trong quá trình tiến hành đo chức năng hô hấp phụ thuộc nhiều vào sự hợp tác của người bệnh nên có thể ghi nhận nhiều trường hợp có hội chứng tắc nghẽn hơn thực tế. Nghiên cứu cho thấy đa số đối tượng có hội chứng hạn chế là ở mức độ nhẹ, trong khi đó ở những người có hỗi chứng tắc nghẽn mức độ vừa lại chiếm tỷ lệ cao nhất. Kết quả của chúng tôi chênh lệch so với nghiên cứu của Ngô Thùy Nhung với rối loạn thông khí tắc nghẽn mức độ nhẹ cao $(66,7 \%)$, rối loạn thông khí tắc nghẽn nặng (19,0\%), người bệnh bị rối loạn thông khí tắc nghẽn rất nặng chỉ chiếm $1 / 21$ bệnh nhân ${ }^{13}$. Kết quả này cũng có sự khác biệt so với nghiên cứu của Lê Thị Hằng trên công nhân sản xuất vật liệu xây dựng, 15,8\% có biểu hiện rối loạn thông khí trong đó rối loạn thông khí hạn chế chiếm tỷ lệ cao nhất. ${ }^{14}$ Trên những bệnh nhân có rối loạn chức năng hô hấp có thể tăng trên $300 \%$ khả năng tử vong do bệnh đường hô hấp và tăng nguy cơ tử vong do ung thư phổi lên tới $80 \%{ }^{15,16}$ Trong thực hành lâm sàng, việc xuất hiện các bất thường trong chỉ số chức năng hô hấp sẽ giúp bác sĩ đánh giá chính xác tình trạng nặng của bệnh, điều trị hợp lý để cải thiện triệu chứng khó thở cho bệnh nhân. Đối với bệnh nhân mắc bệnh bụi phổi silic, đo chức năng hô hấp giúp đánh giá mức độ nặng của bệnh, tình trạng suy hô hấp để có những biện pháp điều trị hiệu quả nhằm nâng cao chất lượng cuộc sống cho bệnh nhân trong bối cảnh bệnh còn chưa có thuốc điều trị đặc hiệu. Mặc dù bệnh gây ra những hậu quả nghiêm trọng, tuy nhiên không phải nhà tuyển dụng nào cũng chấp nhận bồi thường cho người lao động do bệnh nghề nghiệp mà họ mắc phải. Vậy nên chính người lao động cần phải chủ động tự bảo vệ mình bằng cách tuân thủ các quy tắc về an toàn lao động, mang đầy đủ các trang thiết bị bảo hộ cá nhân để hạn chế tiếp xúc với bụi silic. Ngoài ra, các nhà quản lý cần có những quy định chặt chẽ đối đối với chủ doanh nghiệp trong việc sử dụng lao động.

\section{KÉT LUẦN}

Tỷ lệ bệnh nhân bệnh bụi phổi silic có rối loạn thông khí hạn chế là 23,3\%; rối loạn thông khí tắc nghẽn là $23,3 \%$ và rối loạn thông khí hỗn hợp là 12,7\%. Trong số đối tượng có rối loạn thông khí hạn chế, đa số là ở mức độ nhẹ $(60,0 \%)$, rối loạn thông khí hạn chế mức độ nặng chiếm 30,0\% và rối loạn thông khí mức độ vừa chiếm 10,0\%. Trong số đối tượng có rối loạn thông khí tắc nghẽn, mức độ vừa chiếm tỷ lệ cao nhất (45\%), tiếp theo là rất nặng $(25,0 \%)$, nặng $(20,0 \%)$ và nhẹ $(10,0 \%)$. Khi điều trị bệnh nhân bệnh bụi phổi silic cần đánh giá cả chức năng hô hấp để đưa ra các phương pháp điều trị hiệu quả nhất vừa làm chậm quá trình xơ phổi và cái thiện triệu chứng cho bệnh nhân.

\section{TÀl LIẸU THAM KHẢO}

1. Bộ Y tế. Thông tư 15/2016/TT-BYT bệnh nghề nghiệp được hưởng bảo hiểm xã hội. Thư viện pháp luật. truy câp. 20/12/2020. https:// thuvienphapluat.vn/van-ban/Bao-hiem/Thongtu-15-2016-TT-BYT-benh-nghe-nghiep-duochuong-bao-hiem-xa-hoi.

2. Bộ Y tế. Bệnh bụi phổi silic nghề nghiệp và hướng dẫn chẩn đoán. truy cập 20/12/2020, https://moh.gov.vn/web/phong-chong-benh-nghenghiep/thong-tin-hoat-dong/-lasset_publisher.

3. Fernández Álvarez R, Martínez González C, Quero Martínez A, at al. Guidelines for the diagnosis and monitoring of silicosis. Archivos de bronconeumologia. Feb 2015;51(2):86-93. doi:10.1016/j.arbres.2014.07.010.

4. Thomas CR, Kelley TR. A brief review of silicosis in the United States. Environmental health insights. May 18 2010;4:21-6. doi:10.4137/ehi.s4628. 
5. Wang X, Yano E. Pulmonary dysfunction in silica-exposed workers: a relationship to radiographic signs of silicosis and emphysema. American journal of industrial medicine. Aug 1999;36(2):299-306. doi:10.1002/(sici)10970274(199908)36:2<299::aid-ajim9>3.0.co;2-w.

6. Wang X, Yano E, Nonaka K, et al. Respiratory impairments due to dust exposure: a comparative study among workers exposed to silica, asbestos, and coalmine dust. American journal of industrial medicine. May 1997;31(5):495-502. doi:10.1002/(sici)10970274(199705)31:5<495::aid-ajim2>3.0.co;2-t.

7. Yang SC, Lin YF. Airway function and respiratory resistance in Taiwanese coal workers with simple pneumoconiosis. Chang Gung medical journal. Jul-Aug 2009;32(4):438-46.

8. Ulvestad B, Lund MB. [Increased risk of chronic obstructive pulmonary disease among tunnel construction workers]. Tidsskrift for den Norske laegeforening: tidsskrift for praktisk medicin, ny raekke. Aug 28 2003;123(16):22925. Tunnelarbeid gir okt risiko for kronisk obstruktiv lungesykdom.

9. International Labour Organization. Guidelines for the use of the ILO international classification of ragiographs of pneucomoniosies. Revised edition 2000.

10. International Labour Organization. Guidelines for the use of the ILO international classification of ragiographs of pneucomoniosies. Revised edition 2011.

11. Lê Hoài Cảm, Nguyễn Ngọc Sơn. Tỷ lệ nhiễm bụi và đặc điểm lâm sàng $X$ - quang, thông khí phổi của công nhân mắc bệnh bụi phổi silic tại xí nghiệp tàu thủy Sài Gòn. Tạp chí Y học thực hành. 2012;817(4):trang 29-33.

12. Lưu Văn Hoát. Góp phần nghiên cứu bệnh phổi nhiễm bụi silic (silicosis) trong công nhân vùng mỏ than Quảng Ninh. Luận án Tiến sĩ. Đại học Y Hà Nội; 1983.

13. Ngô Thùy Nhung, Khương Văn Duy. Đặc điểm lâm sàng và cận lâm sàng của bệnh nhân mắc bệnh bụi phổi đến khám và điều trị tại Bệnh viện Phổi Trung ương từ tháng 6/2015 đến tháng 12/2016. Luận văn tốt nghiệp. Đại học Y Hà Nội; 2017.

14. Lê Thị Hằng. Nghiên cứu đặc điểm dịch tễ học bệnh bụi phổi silic ở công nhân sản xuất vật liệu xây dựng và hiệu quả biện pháp can thiệp. Luận văn. Đại học Y Hà Nội; 2007.

15. Rosenman KD, Reilly MJ, Kalinowski D, and at al. Silicosis in the 1990s. Chest. Mar 1997;111(3):779-86. doi:10.1378/ chest.111.3.779

16. Manno M, Levy L, Johanson G, et al. Silica, silicosis and lung cancer: what level of exposure is acceptable? La Medicina del lavoro. Dec 20 2018;109(6):478-480. doi:10.23749/ mdl.v109i6.7928 


\section{Summary \\ RESPIRATORY DYSFUNTION IN SILICOSIS PATIENTS AT NATIONAL LUNG HOSPITAL IN 2020}

This study described pulmonary ventilatory disorders in patients with silicosis. The patients were recruited from the Department of Occupational Lung Disease, National Lung Hospital. Interviews were conducted with 86 patients and spirometry analysis was done using their medical records. The results showed that $23.3 \%$ of the participants had restrictive ventilation disorders, $23.3 \%$ had obstructive ventilatory disorders and $12.7 \%$ had mixed ventilatory disorders. Among the participants with restrictive ventilatory disorders, $60.0 \%$ were mild $(60.0 \%), 30.0 \%$ were severe, and $10.0 \%$ were moderate. Among those with obstructive ventilatory disorders, $45 \%$ were severe or higher, $45.0 \%$ were moderate, and $10.0 \%$ were mild. There should be support and guidance on preventive measures for people with silicosis.

Keywords: Silicosis, National Lung Hospital, respiratory dysfuntion. 